\title{
EDUCATION FOR ENVIRONMENT SUSTAINABILITY: 3D PRINTING'S ROLE IN TRANSFORMATION OF PLASTIC INDUSTRY
}

\author{
Haishang Wu \\ Waseda University, Shinjuku, Tokyo, Japan
}

\begin{abstract}
This paper aims to introduce the education and the role of $3 D$ printing (3DP), focusing on its contribution and impact on plastic industry. The goal is to provide solution for increased plastic production and disposal, seeking effective methods to enable 3DP technologies and applications. Recycling of feedstock and reduction of material usage is the main solution in discussion.
\end{abstract}

Key words: Environment, Sustainability, 3D Printing, Economies, Education

Cite this Article: Haishang Wu, Education for Environment Sustainability: 3D

Printing's Role in Transformation of Plastic Industry, International Journal of Advanced Research in Engineering and Technology, 10(4), 2019, pp. 128-134. http://iaeme.com/Home/issue/IJARET?Volume=10\&Issue $=4$

\section{INTRODUCTION}

Additive manufacturing (AM) was launched in 1980's, while the terminology has been changed to $3 \mathrm{D}$ printing (3DP). Both have same definition, that "A manufacturing process of merging materials, to make objects from 3D model data, through layer upon layer, as opposed to subtractive manufacturing methodologies, such as traditional machining". 3DP manufactures 3-dimensional products from physical materials, by means of computer and automatizationbased devices. Products vary in size and shape.

Usually, plastic, ceramic and metals are used as materials. Flexibility of selection of material and autonomy of product design is noteworthy. The cost of machines has been decreasing continuously, from initial price at around $\$ 20,000$ to the price of a few hundred dollars, although the price vary depending on the quality of machine.

3DP was initially known as "additive manufacturing" in 1980s, when equipment and materials were developed. The technology was invented by Japanese inventor Hideo Kodama in 1981. The term "additive manufacturing" is still synonymous with the term "3D printing", only that the nuance is slightly different, as "3D printing" is a rather vernacular and general term, while "additive manufacturing" is more formally used in industrial communities.

The terms are synonymous in this paper. However, the term "3DP" is used, to refer to the technology of additive manufacturing with computer-aided designing, particularly shedding light on its on-demand function of manufacture. Education and skills development in relation 
to 3DP for CE can be considered from several perspectives: 3DP understanding and awareness, skill development and policy making.

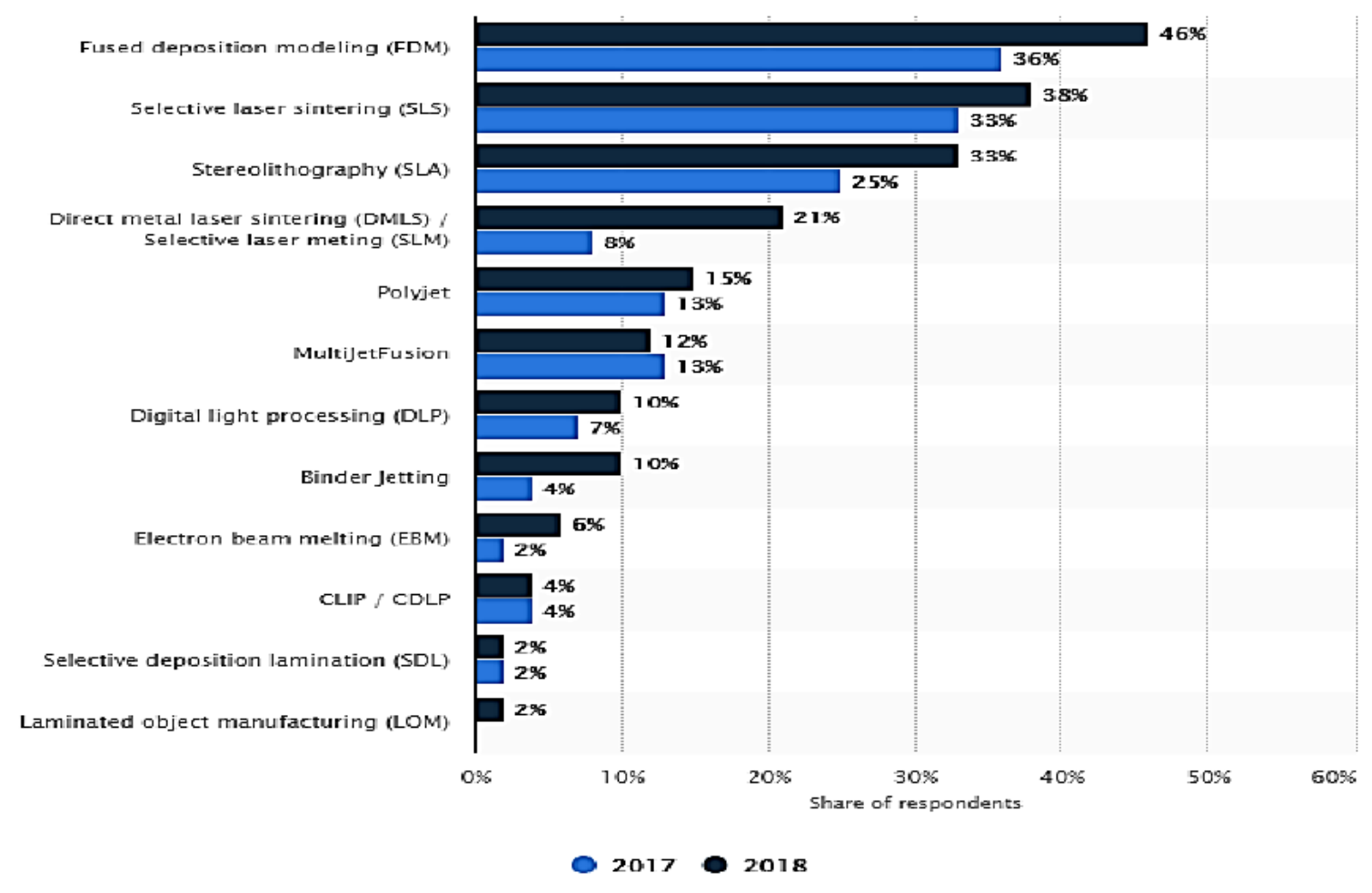

Figure 1. 3DP technologies trend

\section{TECHNOLOGIES}

In general, products are formed by printing materials layer after layer. 3D modeling technology is used to develop mathematical representation of surfaces of objects in three dimensions by specialized software. The most common type of technology used in 3DP is fused deposition modeling (FDM).

As indicated in figure 1, the online survey conducted by "The Statistics Portal" in 2017 and 2018, toward over 1000 users of 3DP technology worldwide demonstrates the trend.

(https://www.statista.com/statistics/560304/worldwide-survey-3d-printing-toptechnologies/ ), FDM technology ranked the top as most frequently used technology of 3DP in both years. It was followed by selective laser sintering (SLS) and stereolithographic (SLA) technology.

In FDM technology, plastic filament is extruded out through a heated nozzle that moves. Additive method is applied, that the material is served layer after layer, into desired shapes. Regarding the pros and cons of FDM, being referred as 3DP technology's "workhorse", it is one of the fastest technologies, to be able to accomplish parts in a few days.

Freedom of shaping is also FDM's advantage, but layer steps can be visible in final products due to its additive process, thus may not be aesthetically desirable. The most common material for FDM is ABS polymer, but other types of plastic such as polycarbonate, polyamides, and polystyrene are also used.[1]

SLS is also an additive technology that powders or small particles of materials are fused into a mass by high power laser, to be shaped into any desired forms. This technology has also a high extent of freedom regarding selection of materials. Compared with FDM, final products are smoother by using SLS. However, SLS devices are more expensive. 
The third popular technology, SLA, uses photo polymerization, a process by which light causes chains of molecules to form into polymers. The polymers are then solidified into the desired shapes. Advantage of SLA is the ability to manufacture in short time, although the equipment is costly. All the three technologies use additive method.

\section{APPLICATIIONS}

3D printing has a wide range of usage at all levels, and has big potential in contributions. To put it simply, we can use 3DP in doing or creating almost anything we wish. Its main usages are commercial or aesthetic design and construction, but it is also possible to be used in medical treatments, such as tissue and organ fabrication, and even used in archeology for the purpose of cultural preservation. Rapid prototyping technology allows it to fabricate 3-dimensional models instantly with help of CAD (computer aided design). Researchers in Cornell University developed "Hydrocolloid Printing" to apply 3DP technology into food industry. This video [2]reveals the various possibilities 3DP can bring to the workshop. Customized tools, such as dust collection system, and all kinds of delicate features, for instance, a small cut to fit in certain tools, can be easily applied.

\section{ANALYSIS OF PLASTIC INDUSTRY}

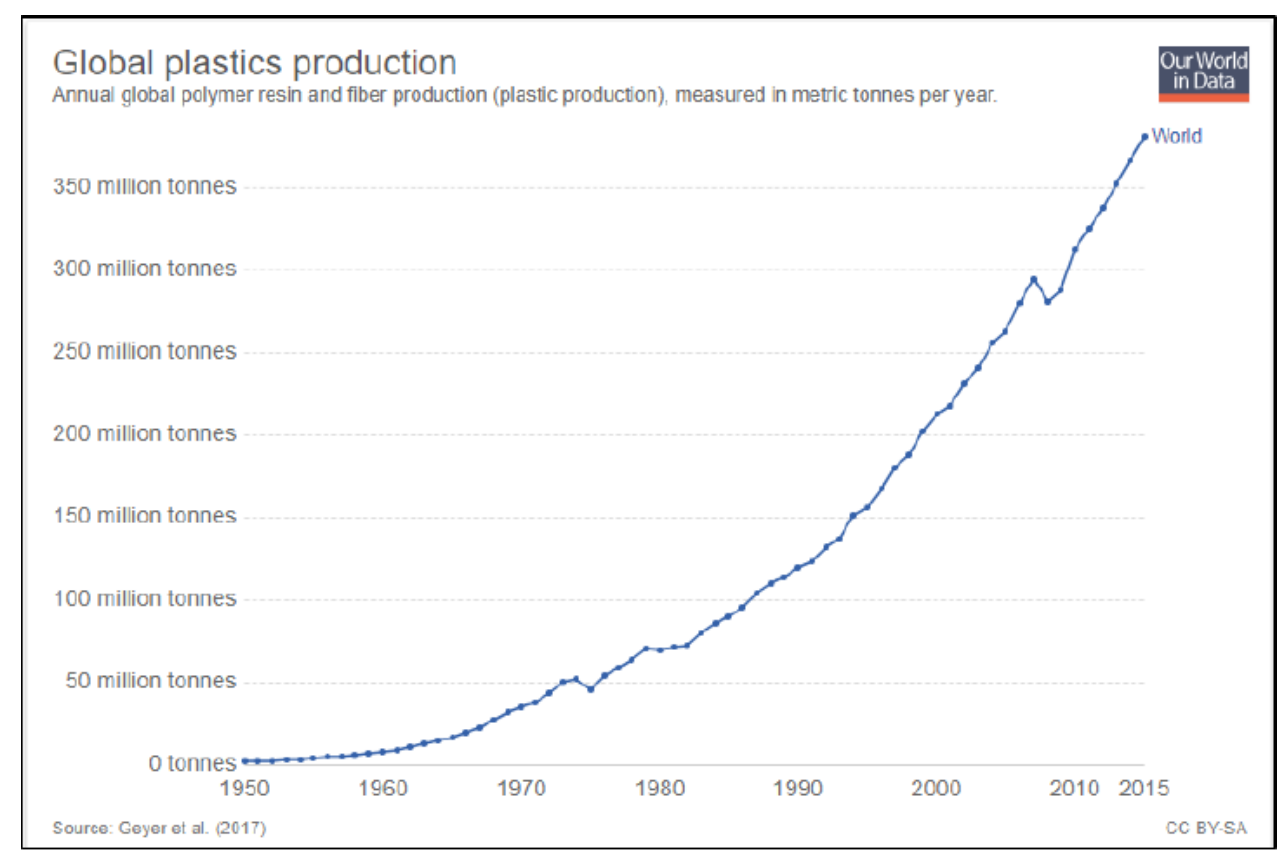

Figure 2. Global plastic production

As indicated in figure 2, mass production of plastic started in the 1950s. In 2015, the amount of production has reached 381 million tons, increasing around 200 -fold over 65 years 3 ]. It is estimated to grow into annual production of 850 million tons by 20504].

Compared to other materials, plastic is mass-produced, due to several beneficial features exclusive to plastic materials. It is durable, light-weighted, more flexible, less fragile, less costly easier to manufacture, and ensures longer preservation time for food products. However, its durability is not only an advantage, but a fatal drawback as well, since plastic products usually take a very long time to decompose, which some may even never break down, and this creates a huge burden for the environment. Plastic products that are disposed and fail to decompose or be processed engender menace to land, waters, ocean, and wildlife. The dominant sector of both the plastic's production and disposal is the packaging sector, which accounted for $42 \%$ of 
production in 2015, and around a half of total disposal in the same year. Waste generation rate of the packaging sector exceeds other sectors to a large extent, due to its short in-use lifetime.

There is currently economic and environmental motivation to recycle plastic products, due to surging material price and rising awareness of environmental protection. According to M. A. Kreiger et.al (2014), commonly recycled plastic types at the moment includes: 1) polyethylene terephthalate (PET), 2) high-density polyethylene (HDPE), 3) polyvinyl chloride (PVC), 4) low-density polyethylene (LDPE), 5) polypropylene (PP), 6) polystyrene (PS), and 7) "other", which is primarily polycarbonate (PC) and acrylonitrile butadiene styrene (ABS).

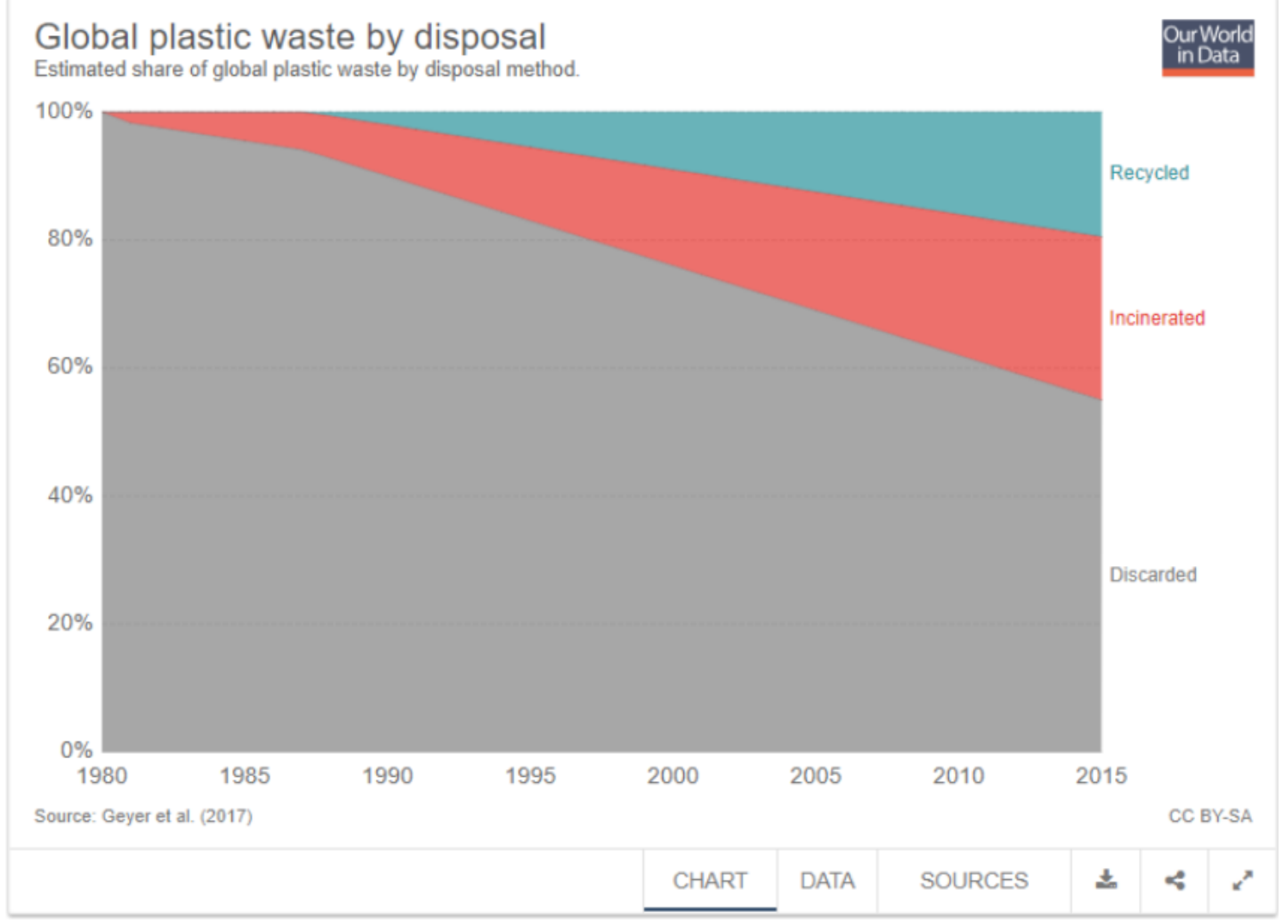

Figure 3. Recycling trend review

Many plastic products result in disposal after single-use. Disposal method of the first decades after the mass production was by discarding exclusively, and at the beginning of the $1980 \mathrm{~s}$, incineration method appeared as an alternative. At around the turn of the 1990s, recycling method was introduced. In 2015, 19.5\% of global plastic waste was recycled, $25.5 \%$ incinerated, and the remaining $55 \%$ discarded. There is a fast growing trend of recycling, faster than that of incineration method. This is shown in figure 3.

\section{BUSINESS ISSUES}

This paper investigates the existing issues of recycling and dependencies of 3DP.

[1] Institutional trust, quality and the state are important for establishing recycling behavior (top-down approach) - N. Harring et al. 2018. The more actors respond to action, the more likely the state to facilitate the programs (bottom-up).

[2] Material needs as cause of industrial emission and waste. But assessment usually from the perspective of technological solution and energy efficiency rather than seeking methods to curtail causes and source of emission. K. Scott et al. 2018 
[3] Open-source projects such as "RepRap" can empower the 3DP community, to develop equipment and technology in more efficient ways. Initiated in University of Bath, England, "RepRap" was developed as a low-cost 3D printer that is able to self-replicate its components. Equipment of RepRap is economically feasible, and is able to manufacture a variety of products without big scales of industry foundation. B.T. Wittbrodt (2013) state that RepRap is economically attractive since it saves considerable costs when printing common products. Since it reduces material costs, it can also imply that less resource is used, thus more environmentally friendly. M. A. Kreiger et.al (2014) reveal that "the primary expense of operating a 3-D printer is the filament or "3-D ink" and thus the operating costs of the RepRap can be further reduced using post-consumer plastics as feedstock' [5]. "RecycleBot" is the technology that manages to recycle post-consumer plastic into feedstock.

[4] Distributed or decentralized recycle of polymers is more economically feasible since it eliminates extra costs on transportation. Process emission is one of the negative impacts to be avoided in recycling. Reduced assembly lines and supply chain can not only save materials and costs, but also saves a lot of time, considering time as a kind of resource. Conventionally, different components forming a product were manufactured separately, with designated sequence of composition. With globalization and division of component manufacturing across countries, shipping and transportation requires additional investments.

[5] Digitalization and virtualization of designs can save a lot of unneeded and redundant materials used for conventional production [6]. Just like the internet has managed to store and transfer information in virtualized formats, 3DP has reached a new milestone for the industry that it enables virtualization of materials.

\section{DISCUSSIONS}

Education and skills development in relation to 3DP can be considered from several perspectives: 3DP understanding and awareness, skill development and policy making. How could 3D printing foster the education around the value of materials and recycling has become a major topic in waste management of plastic industry. About $45 \%-52 \%$ of the plastic bottles are collected for recycling in the UK. $97 \%$ of the recovered plastics from municipal waste are within the co-mingled waste stream and sorted out at Material Recovery Facilities (MRFs). The plastics recycling rate is rather low, estimated to be only $16 \%$. Plastic PET bottles sorted, cleaned and turned into flakes. The yield of this process varies between $45-75 \%$; losses are due to contamination of the baled PET bottles.

As 3DP become more commonly available, it is likely that the exchange of materials, products and information related to $3 \mathrm{D}$ printers will increase. Business models can evolve around the various processes in the production supply chain, from raw material and 3D model suppliers to manufactures of complex3Dprintedparts. As products become increasingly locally manufactured, the local distribution of goods will intensify. Since the production could take place at the nearest suitable 3D printer having printing capacity, this could offer opportunities for automation software determining the optimal print location.

The economics of scale currently involved in the (plastics) recycling industry limits the use of local materials. At the same time, margins on recycled plastics are low due to the low prices of virgin plastics, which is an extra incentive for large scale recycling to reduce recycling costs. Further, the consumers of recycled plastics (e.g. plastic packaging manufacturers) operate at a large scale as well, which stimulates large scale recycling too. When 3D printers become more affordable, value creation increases, but it can become more difficult to capture this value, since competitors can easily adapt their business strategies to the changing market conditions. 
Therefore it is likely that the competition among businesses will increase. A large amount of plastic bottles is still hard to sort out from the waste streams.

The plastics PET and HDPE are already largely recycled and huge quantities exist in the household waste stream, mainly in the form of plastic bottles. There is a strong market for recycled plastic bottles, but decreasing oil prices may impact the plastic recycling market, since the price difference with virgin plastics becomes smaller.

\section{CONCLUSIONS}

3DP is proposed as a tool to enable design for waste management and consequently impacts circular economies. However, without a comprehensive understanding of the characteristics of the technology, benefits from all entities, policies, transformation, and resulting products that can align with circular economies principles, its use could be ill fated.

Education and skills development in relation to 3DP for circular economies is critical to envision the consensus and collaboration between multi-entities (such as business owner, designer, consumer, law-maker, environment engineer, and manufacturer. In order to resolve the business issues of current stage, technologies, policies and consumer's behavior are key factors to escalate and promote 3DP to a higher level, to support waste recycling and circular economies.

\section{REFERENCES}

[1] 3D Printing: Fused Deposition Modeling (FDM) http://www.pongratzengineering.com/2014/09/26/3d-printing-fused-deposition-modeling-fdm/

[2] "Is 3D printing worth it?", Marius

Hornberger,https://www.youtube.com/watch?v=k8mzMDLqENA (retrieved 12/29/2018)

"Plastic Pollution", Hannah Ritchie and Max Roser, Our World in Data, (2018)

[3] "Could 3D Printing Change the World? Technologies, Potential, and Implications of Additive Manufacturing", Thomas Campbell et.al (2011)

[4] “3D PRINTING: FUSED DEPOSITION MODELING (FDM)”, Yvonne Ng, (http://www.pongratz-engineering.com/2014/09/26/3d-printing-fused-deposition-modeling$\mathrm{fdm} /$ )

[5] “3-D Printing of Open Source Appropriate Technologies for Self-Directed Sustainable Development", J. M Pearce (2010)

[6] "Apparatus for production of three-dimensional objects by stereolithography", U.S. Patent 4,575,330 (https://patents.google.com/patent/US4575330A/en )

[7] "Could 3D Printing Change the World? Technologies, Potential, and Implications of Additive Manufacturing", Thomas Campbell et.al (2011)

[8] Abioye, O. P, Abioye, A. A, Afolalu, S. A, Akinlabi, S. A and Ongbali, S.O, A Review of Biodegradable Plastics in Nigeria, International Journal of Mechanical Engineering and Technology, 9(10), 2018, pp. 1172-1185.

[9] "Hydrocolloid Printing: A Novel Platform for Customized Food Production", Daniel L. Cohen (2009)

[10] "Life Cycle Analysis of Distributed Recycling of Post-consumer High Density Polyethylene for 3-D Printing Filament”, M. A. Kreiger et.al, Michigan Technological University (2014)

[11] "Life-cycle economic analysis of distributed manufacturing with open-source 3-D 
Education for Environment Sustainability: 3D Printing's Role in Transformation of Plastic Industry

printers", B.T. Wittbrodt et.al, (2013)

[12] "Medical Applications for 3D Printing: Current and Projected Uses", C. Lee (2014) (https://www.ncbi.nlm.nih.gov/pmc/articles/PMC4189697/)

[13] "Plastic Pollution", Hannah Ritchie and Max Roser, Our World in Data, (2018)

[14] A. Ramya and Sai leela Vanapalli, 3d Printing Technologies in Various Applications. International Journal of Mechanical Engineering and Technology, 7(3), 2016, pp. 396-409. 